\title{
A LOJA DE MOHAMED. ESPAÇOS TRANSNACIONAIS, PRÁTICAS MUÇULMANAS E RELAÇÕES DE GÊNERO ENTRE MIGRANTES SENEGALESES NUMA PEQUENA CIDADE DO RIO GRANDE DO SUL
}

\author{
Mohamed's store. Transnational spaces, Muslim practices and gender \\ relations among Senegalese migrants in a small city in Rio Grande do Sul
}

\author{
Margarita Rosa Gaviria Mejía* \\ Marcele Scapin**
}

\begin{abstract}
Resumo. Este artigo aborda experiências migratórias de senegaleses e as conexões transnacionais que dão suporte a esse fluxo migratório, fundamentado em princípios religiosos muçulmanos da confraria murid. As reflexões apoiam-se numa pesquisa etnográfica realizada em Lajeado, Rio Grande do Sul. O eixo de análise são as trajetórias de vida de migrantes das quais nos aproximamos na Loja de Mohamed, qualificada como espaço transnacional, com ênfase nas relações de gênero instituídas com base no muridismo. $\mathrm{O}$ artigo contribui para pensar relações de gênero e dar visibilidade aos migrantes senegaleses em Lajeado, contingente migratório que não aparece no registro da distribuição de migrantes senegaleses no Rio Grande do Sul.
\end{abstract}

Palavras-chave: migração; murid; senegaleses; Rio Grande do Sul, gênero.

\begin{abstract}
This paper addresses the specificities of Senegalese migratory experiences and the transnational connections that support this migratory flow, based on Muslim Mourides' principles. The reflections are grounded on ethnographic research carried out for two years in a small city of Rio Grande do Sul. The analysis focuses on life stories of migrants whom we have met at Mohammed's store, qualified as a transnational space, and emphasizes particularities of these stories observed in gender relations laid down by Mourides. This study deals with gender relations and gives visibility to this migratory contingent, which does not appear in the record of the Senegalese migrants distribution in this state.
\end{abstract}

Keywords: migration; Muslim Mourides; Senegalese; Rio Grande do Sul; genre.

\footnotetext{
Programa de Pós-graduação em Ambiente e Desenvolvimento da Universidade do Vale do Taquari-Univates. Lajeado - RS, Brasil. E-mail: margaritarosagaviria@gmail.com. Orcid: 00000002-1522-3464.

** Doutoranda do Programa de Pós-graduação em Ambiente e Desenvolvimento da Universidade do Vale do Taquari-Univates. Lajeado - RS, Brasil. E-mail: cele_scapin@yahoo.com.br. Orcid: 0000-0003-1956-129X.
} 


\section{Introdução}

Os movimentos migratórios internacionais de senegaleses direcionam-se para o Brasil nas primeiras décadas de século XXI, quando as rotas migratórias para a Europa e os Estados Unidos se esgotam pelo controle nas fronteiras (Tedesco, 2017; Heredia, Gonçalves, 2017). Na mobilidade de senegaleses para o Brasil se inspiram as reflexões apresentadas neste texto, fundamentadas numa pesquisa etnográfica realizada em Lajeado, cidade de 80.000 habitantes no Rio Grande do Sul, Brasil, marcada por dois fluxos migratórios. O primeiro corresponde à chegada de alemães e italianos, no final do século XIX e inícios do XX, num contexto histórico em que o governo brasileiro procura "o branqueamento da raça através [...] da imigração europeia" e condena as migrações negras porque comprometem o processo de branqueamento (Seyferth, 1994, p. 181-182). O outro fluxo migratório, na segunda década do século XXI, acontece com a vinda de migrantes de países como Haiti, Senegal, Bangladesh e Gana, entre outros, atraídos pelas oportunidades de trabalho oferecidas por empresas da cidade.

Lajeado é uma pequena cidade ocupada por uma população com identidade cultural cristã europeia que, a partir de 2011, passa a ser cenário da mobilidade de senegaleses seguidores da confraria murid, ligada à religião muçulmana. Nessa cidade, os migrantes senegaleses-muçulmanos vinculam-se a duas indústrias de alimentos, produtoras e exportadoras de frango, através de empresas transnacionais $\mathrm{CDIAL}^{1}$ e $\mathrm{CIBAL}^{2}$, terceirizadas, encarregadas do abate dos frangos, seguindo os preceitos da religião muçulmana - requisito necessário para que as indústrias de alimentos obtenham o Certificado Halal, que garante a exportação para países muçulmanos. Outro espaço de atuação dos senegaleses em Lajeado é o comércio, sendo as vendas ambulantes a modalidade mais comum, prática valorizada culturalmente porque lembra a trajetória do profeta Cheikh Ahmadou Bamba Mbacké (Buggenhagen, 2011). Nesse sentido, conforme Glick-Schiller e Çaglar (2011), através de diversos percursos, os migrantes se mobilizam em torno das oportunidades oferecidas pelo posicionamento dessa cidade em conexão com relações transnacionais.

Nesse contexto migratório, os senegaleses expressam suas subjetividades nas formas de se relacionar com o mundo, engajam-se no movimento de construção e de produção de si. São sujeitos práticos, com poder de ação, que se constituem num processo que ultrapassa a própria experiência (Deleuze, 2009). Dessa perspectiva teórica, o viés não é numa comunidade diaspórica senão nos migrantes dentro dessa localidade como agentes e sujeitos dessa experiência migratória - experiência fundamentada numa rede de relações que envolve atores na localidade e em campos sociais que ultrapassam fronteiras locais e

Centro de Divulgação do Islam para América Latina.

2 Central Islâmica Brasileira de alimentos halal Ltda- EPP. 
nacionais. A natureza dos vínculos locais e transnacionais presentes nas redes que dão suporte à vida desses migrantes senegaleses revela que a presença feminina é escassa neste contexto migratório. Segundo Uebel (2017), no estado do Rio Grande do Sul, 1,6\% dos migrantes senegaleses é mulher. E na cidade de Lajeado, num contingente de 38 senegaleses, há duas mulheres. Na maior parte dos casos, a participação das mulheres nos projetos migratórios se dá permanecendo no país de origem. Contudo, a voz das mulheres tem menos impacto que a dos homens em decisões que moldam esses projetos (Soares, 2005).

Pesquisas sobre gênero e migrações revelam que a experiência migratória das mulheres não deve ser abordada como derivação da migração dos homens. As mulheres desempenham um papel importante nas migrações, elucidado na análise das diferenças de gênero. Dessa perspectiva, propõe-se dar visibilidade às mulheres e reconhecê-las como sujeitos ativos nas migrações, sem fazer generalizações, já que são diversas as posições que as mulheres ocupam nas migrações internacionais contemporâneas. Nesse contexto há ambivalências, já que, ao mesmo tempo em que as migrações podem significar formas de empoderamento das mulheres, podem também infringir seus direitos primários. Em algumas situações a mulher é vítima e em outras situações agente de mudanças no âmbito pessoal e no social. Sugere-se, então, analisar esses sujeitos evitando estereótipos ou aproximações simples (Marinucci, 2007).

Este texto contribui na análise dos espaços transnacionais e das relações de gênero na experiência migratória senegalesa no sul do Brasil, estruturada com base nos princípios do muridismo. Em Lajeado, os migrantes senegaleses murids encontram condições para construir seus projetos migratórios, mas enfrentam práticas discriminatórias sustentadas numa ideologia racista e xenofóbica da maior parte da população, que evoca uma identidade europeia. Nessa ordem de ideias, o artigo visa complementar estudos de migração senegalesa no Rio Grande do Sul, dando visibilidade a esse contingente migratório em Lajeado que não aparece no registro da distribuição de migrantes senegaleses no Estado (Uebel, 2016), apesar de ser reconhecido e atuar na Federação de Associações de Migrantes Senegaleses no Brasil.

A aproximação às relações dos senegaleses com e na cidade de Lajeado inicia na Loja de Mohamed, uma infraestrutura não oficial da migração, que qualificamos de espaço transnacional, onde sempre fomos calorosamente recepcionadas, ao longo dos dois anos da pesquisa. Nesse período interagimos como amigas, categoria usada pelos senegaleses para reverenciar a proximidade estabelecida nas relações. Fomos convidadas a participar de eventos organizados pela comunidade diaspórica, atuamos como freguesas compradoras de alguns de seus produtos, mas, principalmente, como pesquisadoras interessadas em aprofundar as peculiaridades da experiência migratória de senegaleses em Lajeado. Nossa múltipla inserção no campo gerou uma proximidade 
entre ambas as partes, o que facilitou a elaboração de entrevistas dirigidas e a observação de práticas e acontecimentos. A partir desses instrumentos, construímos este artigo que aborda as experiências migratórias de senegaleses e as conexões que dão suporte a esse fluxo migratório, fundamentado em princípios religiosos muçulmanos da confraria murid, vinculada à ética do trabalho como meio de purificação espiritual, que realça a identidade compartilhada, a piedade e a generosidade econômica para com os líderes murids no Senegal e com os irmãos da diáspora senegalesa (Rosander, 2010). E como qualquer manifestação religiosa, na diáspora, a confraria murid é fonte de afirmação cultural e de participação social, transcendendo as fronteiras do meramente religioso (Guijarro, 2014).

O conhecimento das trajetórias de vida dos migrantes foi construído a partir da Loja de Mohamed, enfatizando nas relações de gênero instituídas culturalmente com base no muridismo, grupo religioso sufi, ao qual estão vinculados os migrantes senegaleses em Lajeado. Essa confraria com grande tradição migratória rural urbana, na atualidade é amplamente ligada à migração transnacional e à capacidade de adaptação a novos contextos sociais nos quais mulheres e homens têm amplo protagonismo, manifesto nos rituais dos ciclos de vida e como responsáveis pela socialização, seguindo os preceitos religiosos do muridismo (Buggenhagen, 2011). Sob a perspectiva de gênero, observamos processos e práticas que envolvem mulheres e homens e suas relações entre si na diáspora em que estão inseridos e nas relações transnacionais.

\section{Loja de Mohamed ${ }^{3}$ : espaço transnacional}

A primeira incursão à pesquisa começou em 2016 quando conhecemos Mame, uma senegalesa aluna do curso de português para estrangeiros, no qual atuamos como professoras. Ela assistia às aulas enquanto gestava seu primeiro filho, e parou de frequentá-las um mês antes do nascimento do bebê. Em março de 2017, a procuramos como canal de imersão à experiência migratória de senegaleses em Lajeado. Como ela tem muita dificuldade de comunicação em português, convidamos uma haitiana para atuar como tradutora. Marcamos encontro com a senegalesa na escola onde as aulas de português eram ministradas, mas ela não compareceu, então a haitiana nos conduziu ao lugar onde Mame estaria, a Loja de Mohamed. Na Loja conhecemos Mohamed, marido de Mame, o qual informou que a esposa tinha ido visitar uma amiga senegalesa em outra cidade.

Desde o primeiro encontro, Mohamed tem sido nosso interlocutor principal e apresentador da comunidade senegalesa em Lajeado, e sua Loja

\footnotetext{
3 Os nomes que aparecem no texto são fictícios. Apenas o de Mame é real, já que seu nome evoca um personagem religioso feminino, da confraria murid.
} 
um espaço de referência na construção dos dados. A análise do significado desse espaço nos permitiu perceber que estar fisicamente em Lajeado é estar ao mesmo tempo em outras localidades no Brasil e até em outros países, porque a partir dele são estabelecidas relações transnacionais. Nesse cenário, os movimentos migratórios são fenômenos sociais complexos, constituídos por relações sociais multissituadas que vinculam as sociedades de origem às de acolhida e àquelas que compõem o trajeto migratório, nos países da América do Sul e nas cidades brasileiras por onde se mobilizam (Mejía, Cazarotto, 2017).

Mohamed é natural de Kour Mbattar, uma cidade da província de Thies, que fica a 110 quilómetros de distância de Dakar, capital do Senegal, onde mora a família, com quem fala quase todos os dias, disse. Ele casou com Mame, sua prima, em 2006, e um ano depois migrou para a Argentina. Em 2011, Mohamed foi visitar a família no Senegal e no retorno para a Argentina parou em Caxias do Sul, Rio Grande do Sul, onde acabou permanecendo porque foi beneficiado pela lei de amnistia aos migrantes de 2009. No Brasil era "mais fácil de obter a documentação", em comparação à Argentina. A experiência migratória de Mohamed evidencia como os tratados internacionais, leis e mudanças legais e exigências documentais interferem em avaliações, itinerários e escolhas migratórias. Confirma a hipótese de que as tecnologias de governamentalidade interferem nos fluxos de vida, e que a migração não é um projeto com todos os elementos controlados pelos sujeitos da migração (Jardim, 2017). Como aponta Babou (2008), inúmeros fatores vinculados ao status legal, à família, e aos contextos sociopolíticos e culturais no país em que se estabelecem afetam a vida dos migrantes.

Em Caxias do Sul, Mohamed trabalhou na empresa Seara Brasil da qual saiu quando foi comprada pela JBS, e modificou as condições de trabalho. A JBS não oferecia mais alojamento e alimentação para os migrantes senegaleses. Em 2014, após uma pesquisa de mercado, Mohamed analisou as possibilidades para montar uma loja em Porto Alegre e em Lajeado, optando por Lajeado. Um dos motivos que contribuiu na escolha por Lajeado foi o de que na cidade reside uma ampla população haitiana $(584)^{4}$ e não havia um negócio comercial que atendesse as demandas desses migrantes contemporâneos, em especial as dos haitianos e dos senegaleses que começaram a chegar à cidade nos anos de 2011 e 2012. Outro fator que favoreceu na escolha foi o de que tinha amigos morando nessa cidade. A trajetória de Mohamed revela que os itinerários migratórios não são marcados meramente por uma troca de lugar no contexto migratório, mas por mudanças no foco em seus projetos e nas ações dos atores implicados no campo de das migrações (Jardim, 2017). Quando migrou para a América do Sul, Mohamed foi levado a transitar por espaços, estimulado pela empregabilidade e pelas condições de integração às localidades.

${ }_{4}$ De acordo com dados da Polícia Federal em 2018. 
O local selecionado por Mohamed para montar a Loja é uma área periférica do centro da cidade de Lajeado, na parte antiga, onde residem senegaleses e haitianos porque o valor dos imóveis é mais acessível. Nesse setor da cidade, os nativos evitam circular por medo de assalto. Qualificamos essa Loja de espaço transnacional porque nela são consolidadas dinâmicas de redes sociais através da mediação tecnológica, das quais participam as comunidades migrantes, familiares e amigos que se encontram em seus países de origem, bem como em outros países. Mohamed possui vínculos comerciais com integrantes de outros países, entre os quais ele destaca Haiti e Colômbia. Para ele "é tudo irmão", utiliza essa categoria de parentesco para evocar igualdade nas relações, pessoas que ocupam a mesma posição social na cidade. Ao mesmo tempo, sua Loja é um local de encontro entre senegaleses. Presenciamos situações em que eles auxiliam no atendimento aos fregueses, e também observamos que alguns vendem as mercadorias da Loja no comércio ambulante de Lajeado.

Mohamed oferece na Loja recursos tecnológicos de diferentes modalidades para comunicação. No início, o espaço comercial tinha uma central telefônica com cinco cabines utilizadas pelos migrantes para se comunicarem com familiares que se encontram em outras nações e não têm acesso à internet. Após quatro anos disponibilizando as cabines telefônicas, ele as retirou para destinar o espaço à exposição de mais mercadorias porque não era rentável, já que o aplicativo WhatsApp suplantou o serviço dos call centers. Atualmente, sua Loja possui duas cabines (foto 1). Um dos produtos que mais vende é o cartão de telefones por meio do link: idealted.com. Há venda de cartões telefônicos internacionais, créditos para celular, prestação de serviço de envio de remessas para familiares no exterior, em dinheiro e espécies. Atua como mediador do Sévis Dirék Pou Ajan (foto 2), empresa que envia alimentos não perecíveis para o Haiti.

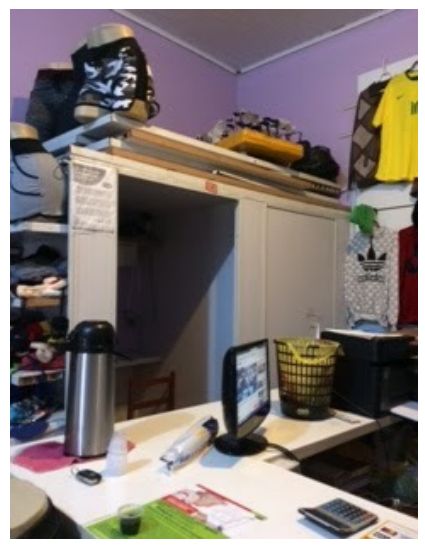

Foto 1 (acervo da pesquisa)

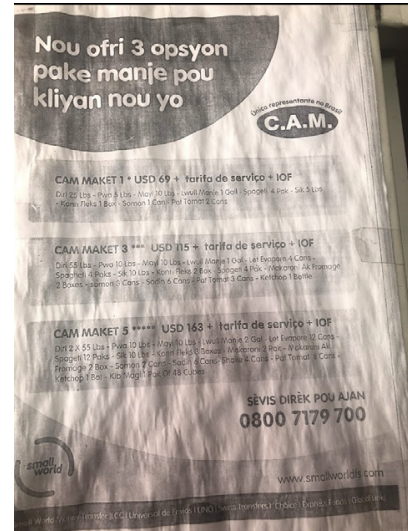

Foto 2 (acervo da pesquisa) 
Não apenas se observa na Loja o fluxo de migrantes de diversas nacionalidades, mas também de mercadorias que transcendem fronteiras nacionais, misturadas com escassos objetos artesanais feitos por senegaleses como o ndiampé, "tecido usado no Senegal para tomar banho", explica Mohamed. Vendem-se capinhas de proteção para celulares, bolsas, meias, luvas, toucas, roupas femininas e masculinas, tênis, sendo a maioria dos produtos trazidos de São Paulo. Segundo ele, os produtos mais vendidos são tênis, roupas (calças jeans) e perfumes (foto 3). Esses produtos são o que Pinheiro-Machado (2011) define como "made in China", e fazem parte de uma cadeia global de mercadorias, dos quais poucos têm consciência de onde vem e para onde vão, objetos que demarcam estilos de vida transnacional. Mohamed, proprietário e gestor do negócio, atua como mediador das relações entre os migrantes, e dos migrantes com os elementos materiais que compõem a Loja.

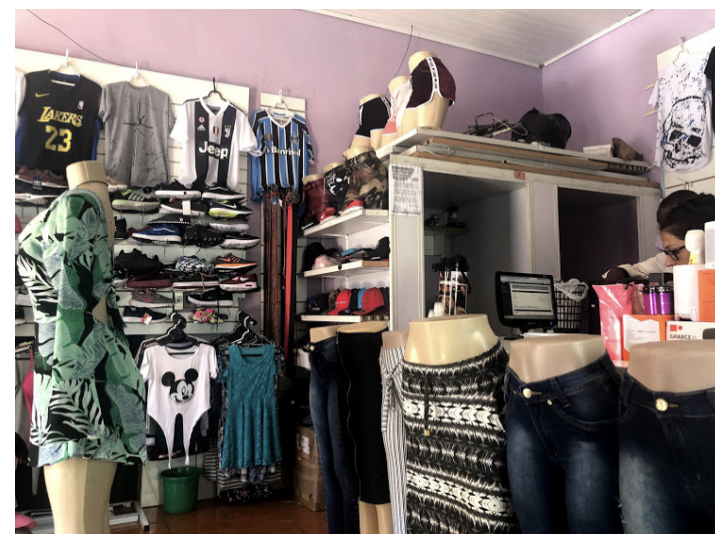

Foto 3 (acervo da pesquisa)

No empreendimento, Mohamed vende a prazo, resolvendo uma dificuldade que atinge os migrantes - a falta de crédito. Os nomes dos credores são registrados em um caderno e à medida que pagam parcelas da dívida Mohamed faz o registro, ou Mame, sua esposa, quando ele não está. Os pagamentos são realizados no início do mês. Por esse motivo, nesse período, a Loja não fecha no final da tarde, como acontece quando o casal tem algum compromisso e precisa se afastar. Permanece aberta de segunda a segunda. Aos domingos há um horário diferenciado, das 16h às 18h30min, único horário que alguns migrantes têm para fazer compras ou efetuar pagamentos.

Nesse espaço transnacional se entrecruzam migrantes senegaleses e haitianos como aconteceu em Brasileia, no Acre, em 2010, quando chegavam à procura de espaços de trabalho. Os visitantes haitianos da Loja de Mohamed aproveitam a rede de wifi para se conectar à internet nos celulares. Chegam 
para adquirir seus serviços e consumir seus produtos ou simplesmente para tomar Café Touba, que Mame prepara e mantém sempre quente numa garrafa térmica, e para comer biscoitos oferecidos. O comportamento dos haitianos é criticado por Mohamed em duas situações: ao escolher o copo grande e não o pequeno para servirem o cafezinho, e quando pedem desconto nas compras. Perpassa uma tensão no ato das negociações com os clientes, diante do qual Mohamed acaba cedendo e baixa os preços.

Contudo, entre os migrantes de ambas as nacionalidades, há manifestações de solidariedade observadas, por exemplo, ao reconhecer as ações do líder dos haitianos, representante dos migrantes e funcionário da prefeitura, em defesa dos senegaleses que desenvolvem comércio de rua. Também são percebidas manifestações de solidariedade ao circular entre eles informações sobre recursos legais e práticos aos quais podem recorrer para melhorar a situação de vida. Uma das ações de solidariedade que acompanhamos - porque fomos chamadas a colaborar - foi quando Mohamed solicitou que ajudássemos alguns haitianos no preenchimento do formulário para inscrição na prova de Proficiência em Língua Portuguesa para Estrangeiros - Celpe-Bras -, desenvolvida pelo Ministério da Educação, necessária para solicitarem a nacionalidade brasileira. Em situações como essas, os migrantes acionam as tecnologias de governamentalidade na experiência migratória. Essas tecnologias interferem e geram arenas de enfrentamento específicas para esses migrantes, visualizadas em seu cotidiano, no acesso aos serviços públicos de saúde, para além do mundo laboral. Assim, a aquisição da Carteira de Registro Nacional Migratório lhes garante o poder de se mobilizar através de fronteiras, situação que evoca mecanismos institucionais que controlam e regulam a mobilidade de pessoas através de fronteiras e operam como marcos dos itinerários dos migrantes. Esses itinerários não se definem apenas por critérios geopolíticos, como a passagem por diversos países, mas também jurídica e politicamente, ou seja, entre regulações e instituições com diferentes escopos e escalas de influência (Jardim, 2017).

$\mathrm{Na}$ Loja, se observam expressões de religiosidade que permeiam todas as dimensões da vida dos senegaleses. Além da música ambiente com cantos religiosos murids, há imagens de líderes religiosos afixadas nas paredes. $\mathrm{Na}$ parte superior da parede, em frente à porta principal, está a imagem de Cheikh Ahmadou Bamba Mbacke, que na memória coletiva dos migrantes, é evocado como o principal guia e protetor dos senegaleses muçulmanos, pertencentes à confraria murid. Protege-os dos males do mundo. Suas ações se vinculam com valores de justiça social, trabalho, disciplina, crença e pertencimento. Os murids pertencem à confraria africana mais recente no universo islâmico, considerada de maior repercussão na África Ocidental e nos contextos diaspóricos dessa organização religiosa na Europa, Estados Unidos, Ásia e América. Do ponto de vista analítico, Chiekh Bamba "é um personagem chave para se entender 
a conformação de um ethos de um islã sufi" (Romero, 2017, p. 276-277). Representa uma devoção partilhada entre homens e mulheres murids nos lugares de residência e de trabalho (Rosander, 2010).

Nas paredes próximas à porta principal da Loja, há, de um lado, a imagem do neto de Bamba, Mbacke Mouhammadou Fadi e do outro lado a imagem de Serigne Saliqu, que "é o último filho de Bamba na terra", afirma Mohamed. Acima da porta principal está pendurado o Alcorão em miniatura, envolto numa sacola para protegê-lo da sujeira (foto 4). Explica que as imagens religiosas Ihe servem de companhia e o Alcorão é uma forma de proteção. A reverência a esses líderes, através das imagens, lembra as ponderações teóricas que colocam os murids como exemplo de uma prática muçulmana africana caracterizada pela submissão aos Sufi Shaykhs (Soares, 2007; Buggenhagen, 2011). Os referidos preceitos religiosos manifestam-se nas relações de gênero, assunto no qual focamos a atenção no próximo item.

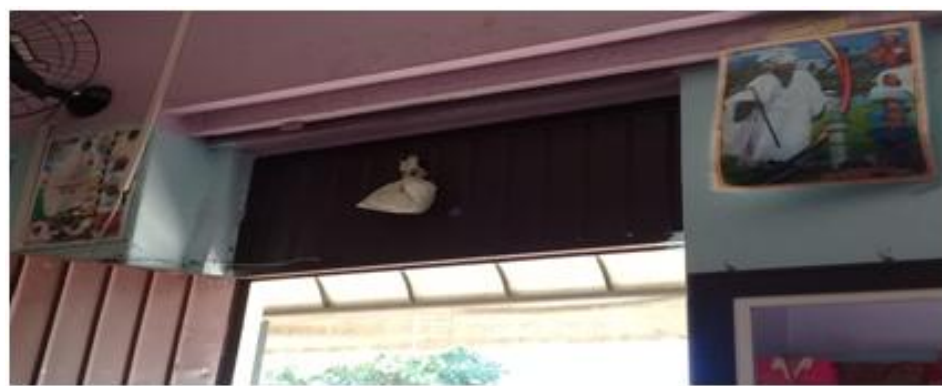

Foto 4 (acervo da pesquisa)

\section{Relações de gênero instituídas culturalmente}

As observações e conversas iniciais sobre a experiência migratória de senegaleses em Lajeado, levantadas a partir da Loja de Mohamed, serviram de lente para pensar as relações de gênero e o papel das mulheres nos projetos migratórios nesse contexto. Para abordar esse fenômeno, nos inspiramos na literatura que aponta que as relações de gênero no contexto migratório se sustentam na reprodução de posições e papéis definidos histórica e culturalmente, neste caso com base no muridismo. Senegaleses e senegalesas envolvidos em projetos migratórios incorporam noções de gênero vinculadas à confraria murid, no âmbito da qual, homens e mulheres atuam de formas diferentes (Babou, 2008). Nos termos de Brah (2006, p. 341), são diversos os significados de ser mulher e de ser homem, cada um deles simboliza "trajetórias, circunstâncias materiais e experiências culturais históricas particulares". Nesse sentido, abordar a experiência migratória de senegaleses vinculados ao muridismo, da 
perspectiva do gênero, permite desconstruir o essencialismo constituinte da diferença dos sexos e compreender a diferença sexual como representação e produto de discursos e práticas institucionalizadas (Sousa, 2011).

Fundamentadas nas considerações teóricas anteriores, indagamos pelas relações de gênero instituídas culturalmente com base no muridismo, discorrendo sobre duas situações: as relações de gênero transnacionais e as relações de gênero na diáspora, distinção analítica que desenvolvemos sustentadas nas teorias do paradigma da mobilidade de Salazar e Glick-Schiller (2014). De acordo com esse paradigma, algumas pessoas participam da migração ficando no país de origem e outras migrando. Segundo esses autores, as pessoas e as práticas culturais não estão circunscritas a um território fixo, mas envolvidas em diversas redes espaciais e vínculos temporais. As categorias espaciais de mobilidade e permanência estão inter-relacionadas, colocando em pauta elementos da mobilidade presentes em situações de imobilidade e vice-versa. No lugar do contraste entre a permanência e a mobilidade, aborda-se o que se mobiliza e o que permanece ao mapear as relações de gênero como uma mistura complexa de estabilidade e movimento. Misturas que se observam nas práticas sociais, mais do que assumidas a priori, em função de que a mobilidade não é só geográfica, mas também social. O paradigma das mobilidades trata as relações entre mobilidade física e social e assinala que a concepção da migração como mobilidade física está estreitamente vinculada à promessa de mobilidade social. A partir desse paradigma, discernimos, a seguir, sobre as duas configurações nas relações de gênero identificadas na pesquisa, uma quando a mulher fica no país de origem, do qual tratamos no tópico relações de gênero transnacionais, e a outra quando homem e mulher migram, abordadas no tópico relações de gênero na diáspora.

\section{Relações de gênero transnacionais}

No contingente migratório de senegaleses em Lajeado, observamos que a maior parte das relações de gênero são transnacionais. Nas narrativas de nossos interlocutores senegaleses que se encontram sozinhos em Lajeado, percebemos que o protagonismo da maioria das mulheres senegalesas nas migrações acontece permanecendo no país de origem, enquanto os homens migram. No Senegal, elas tomam conta dos filhos e idosos, das casas e dos empreendimentos econômicos da família deixados pelos migrantes. As mulheres cumprem a função de dar apoio emocional aos que migram, participam das famílias transnacionais no país de origem, sendo poupadas das dificuldades que enfrentam os migrantes, "como dormir no chão, passar fome e dividir o mesmo teto com inúmeras pessoas", argumenta um senegalês ao explicar o porquê de o contingente feminino entre os migrantes senegaleses no Rio Grande do Sul ser reduzido. Da ótica da ideologia religiosa murid que eles seguem, a migração 
autônoma das mulheres é negativa, a mulher é apreciada principalmente no contexto familiar. De acordo com esses preceitos, as mulheres casadas não deveriam trabalhar fora de casa nem viajar sem seus maridos, e as mulheres solteiras, ou divorciadas, só podem deixar a casa acompanhadas por um homem da família (Rosander, 2010; Sakho et alii, 2015).

Os senegaleses em Lajeado, na posição de maridos, irmãos ou pais que migram, enviam mensalmente para suas mulheres no Senegal remessas de dinheiro para as despesas das famílias na manutenção da "casa", unidade doméstica na qual convivem várias gerações. Os senegaleses seguem os preceitos da cultura murid que valida o casamento poligâmico, num contexto no qual, como disse Rosander (2010), casar é uma obrigação social. Segundo Mbaye, um senegalês que mora na mesma casa de Mohamed e Mame, os homens podem ter até quatro mulheres, desde que consigam sustentá-las e atender às suas necessidades básicas. $\mathrm{O}$ homem e suas mulheres partilham a mesma unidade doméstica e, em caso de morte do marido, os homens de sua família assumem a responsabilidade de sustentá-las (Tedesco, 2017; Heredia, Pandolfi, 2015).

Outra prática que evoca a participação da mulher senegalesa na migração sem se mobilizar do país de origem é casando a distância com um senegalês na diáspora. Dessas celebrações de casamento, sem a presença física do noivo, participa a família do noivo no Senegal. Essa experiência foi vivenciada por Amadou, um senegalês que mora em Lajeado e casou em setembro de 2017. Ele acompanhou no Brasil o ritual de casamento celebrado em seu país, fazendo uso da comunicação virtual. Juntou os recursos financeiros para visitar a família no Senegal em agosto de 2018, viagem que, como ele e outros senegaleses informaram, precisa de dinheiro suficiente tanto para pagar as passagens quanto para cobrir os gastos da família durante o período em que permaneça no país de origem. Isso ocorre porque "por trás de cada emigrante tem uma família que aguarda com esperança e expectativa a concretização do projeto migratório" (Ndiaye et alii, 2015, p. 271).

A exaltação do papel da esposa no Senegal foi percebida ao sabermos que alguns migrantes senegaleses em Lajeado que têm sua esposa no Senegal, como o interlocutor Mbaye, estabelecem relacionamentos amorosos com mulheres brasileiras. Perpassa uma hierarquia nessas relações: as esposas que estão no país de origem têm status diferenciado daqueles relacionamentos que os senegaleses têm com mulheres brasileiras. Mbaye disse que a esposa no Senegal não sabe que ele mora no Brasil com outra mulher. Subjaz a ideia de que os senegaleses não assumem a companheira brasileira como membro da família transnacional, mas das brasileiras não ocultam que deixaram uma esposa no Senegal. Mbaye tinha um relacionamento com uma brasileira, registrado como união estável, e agora procura desfazer essa união para trazer a esposa do Senegal, com quem tem dois filhos. 


\section{Relações de gênero na diáspora}

A ideologia religiosa e cultural da confraria murid na qual se fundamentam os papéis de homens e mulheres é evocada no significado dos nomes. Fato elucidativo é o nome de Mame, quem ao nascer em Koure Mbattar, numa comunidade rural do Senegal, passa a honrar a Mame Diarra Bousso, mãe do Shaykh Amadou Bamba, que representa, como afirma Rosander (2010), um modelo ideal de mulher Mouride: mãe generosa e esposa submissa. Seguindo esse exemplo, Mame casa com Mohamed em 2006, tornando-se uma das esposas de diásporas. Morou com sua família em Ngaye-Meckhe até 2015, quando o marido teve recursos financeiros para que ela viesse residir em Lajeado, e logo depois que chegou, engravidou.

Em situações em que o casal senegalês tem recursos financeiros, a expectativa é de que a mulher participe na condição de migrante, mobilizando-se para morar junto ao marido. Essa condição se assemelha ao que Sarr chama de "migração de acompanhamento" (Sarr, 2012 apud Sakho et alii, 2015), na qual se encontram Mame e Yacine, na cidade de Lajeado. Nas trajetórias migratórias dessas duas senegalesas identificamos formas da participação das mulheres sob a perspectiva de gênero. Observando que nos espaços de migração, as relações de gênero se apoiam na articulação entre esferas produtivas e reprodutivas (Miranda, 2015).

Quanto à esfera produtiva, em alguns espaços migratórios, os maridos pedem às mulheres que contribuam nas despesas diárias domésticas, prática que era considerada responsabilidade dos homens (Babou, 2008; Buggenhagen, 2012). Há um incremento da participação das mulheres nas atividades econômicas, indício de que os casamentos estão passando por uma profunda transformação no Senegal (Rosander, 2010). O envolvimento das mulheres nas atividades econômicas do marido foi observado também nas relações de gênero entre senegaleses em Lajeado.

Yacine chegou a Lajeado em 2017 para acompanhar o marido, líder dos senegaleses residentes na cidade de Garibaldi/RS. Em Dakar, Yacine era comerciante, administrava o negócio do esposo. Atualmente, ela vende, numa esquina movimentada de Lajeado, mercadorias adquiridas pelo marido: bermudas, panos de prato, objetos que o marido lhe ajuda a carregar (foto 5). Não fala português, mas consegue contribuir no negócio do esposo no comércio ambulante nas ruas de Lajeado, conhece o dinheiro e o preço das mercadorias. Ela e o marido trabalham em parceria, cada um fica num ponto diferente da rua, mas em locais próximos, de modo que ele possa ajudá-la, se precisar, e controlá-la. Quando ele viaja para vender em outras cidades, algum conterrâneo se solidariza com o casal e a acompanha na ausência do marido. Numa conversa, o marido dela disse que o projeto familiar é que Yacine o ajude a complementar a renda da família. 
No que diz respeito a Mame, sua atuação nas tarefas da Loja de Mohamed difere quando o marido está presente de quando ele está ausente. Quando Mohamed está, ela fica silenciosa em uma cadeira recuada no fundo do balcão tecendo gorros de lã usados por afrodescendentes, os quais Mohamed vende nas feiras e que, algumas vezes, as haitianas em Lajeado compram para cobrir o cabelo. Já nas ocasiões em que Mohamed não está na Loja porque vai às feiras, sai para fazer diligências na cidade ou a participar de eventos religiosos em outras cidades, Mame fica atrás do balcão, na cadeira onde Mohamed costuma se sentar. Ela vende mercadorias e serviços, e faz cobranças dos clientes que pagam em prestações. Prepara o café Touba, compra biscoitos e balas para recepcionar clientes e visitantes na Loja. Quando Mohamed se ausenta observamos que, em alguns momentos, um conterrâneo a acompanha na Loja.

No ambiente de trabalho, Mame e Mohamed utilizam a Loja como espaço de prática religiosa. Eles oram cinco vezes ao dia, e se o momento da oração acontece estando na Loja, oram ali. Numa ocasião em que estávamos na Loja, observamos que às 15 horas Mame foi ao banheiro, se lavou e, após isso, estendeu o tapete para orar, mesmo que houvesse fregueses no local e que o marido não estivesse, pois era um momento sagrado (foto 6).

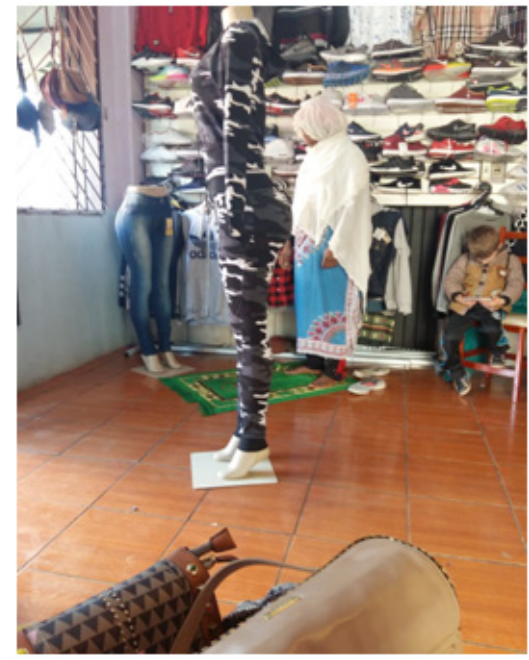

Foto 5 (acervo da pesquisa)

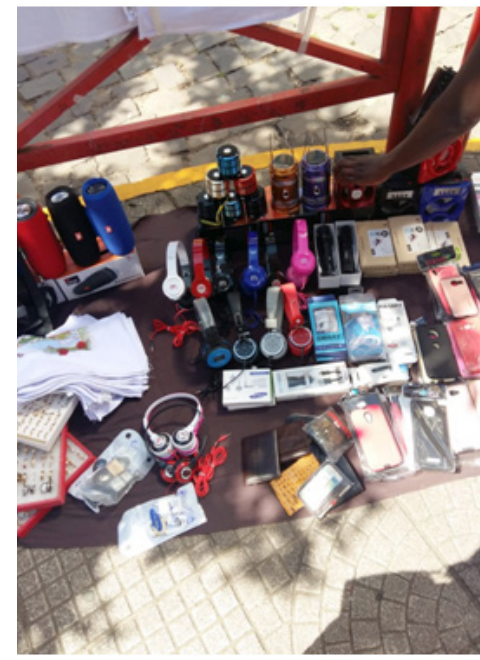

Foto 6 (acervo da pesquisa)

Indagando sobre práticas religiosas murid, observamos que Mame e Yacine, a diferença de seus maridos, não participam dos rituais religiosos em eventos anuais como o Dia de Hassida e o Gran Magal de Touba. Elas também têm algumas restrições religiosas. Quando estão com o ciclo menstrual lhes é proibido ler o Alcorão, e durante o Ramadan, jejuar. Esses mesmos preceitos 
religiosos murids fazem com que a mulher não seja contratada para praticar o abate Halal em indústrias de alimentos. Segundo a lei islâmica, quando a mulher está menstruada, é considerada impura, já que um dos preceitos do islamismo é a limpeza, na conexão com o Deus deve estar limpa de impureza.

Nas trajetórias das senegalesas em Lajeado, as mulheres, além de ajudar seus maridos na comercialização dos produtos, na Loja ou na rua, são as principais responsáveis pela realização das tarefas domésticas. Fazem a limpeza das moradias, lavam roupa e preparam os pratos da culinária senegalesa que os aproximam, simbolicamente, do país. Nos relacionamentos, reproduzem os códigos culturais nos quais se sustenta a vida conjugal.

Mame e Yacine e seus respectivos maridos reproduzem, social e biologicamente, as famílias para além das fronteiras do país de origem. Mame e Mohamed tiveram uma filha em setembro de 2016 e outra em janeiro de 2019. As meninas, assim como o filho de Yacine, têm dois nomes: um na língua do país de origem e outro em português. Fenômeno que traduz o interesse dos migrantes em vincularem suas crianças "brasileiras" tanto à cultura do país de origem quanto ao Brasil. Esses nomes duplos são também resposta às exigências no cartório da cidade de Lajeado, onde é solicitado que, no registro de nascimento, o nome escolhido para a criança exista no Brasil. Apesar de que no cartório justifiquem essa regra como uma norma brasileira, este controle no nome das crianças, que acontece nesta cidade, difere da realidade em metrópoles brasileiras como Rio de Janeiro, onde existem nomes muçulmanos devido à migração anterior (libanês e sírio). Apoiadas em Jardim (2017), argumentamos que esses fatos, como o controle oficial do nome dos filhos de migrantes que nascem no Brasil, ao não terem enquadramento prévio na agenda política brasileira, demandam respostas institucionais.

A situação das duas mulheres (Mame e Yacine) no âmbito das famílias transnacionais difere porque Mame gestou suas duas filhas em Lajeado, e o filho de Yacine nascido em Lajeado, em março de 2019, é o terceiro. Ela deixou no Senegal dois filhos, um de treze e outro de sete anos aos cuidados da mãe. Sua situação lembra o argumento de Winters (2014) sobre os cuidadores da família, de que a mãe representa o membro da família preferido na escolha da cuidadora dos filhos. Yacine e sua mãe desenvolvem um dos inúmeros casos de "maternidade compartilhada" na estratégia migratória. Esse cuidado familiar transnacional influencia nas decisões relacionadas à migração, fundamenta-se em dinâmicas de poder intrafamiliar, no âmbito do qual é relevante o papel desempenhado, direta ou indiretamente, pela família extensa.

O protagonismo da mulher que dá à luz um filho é observado ao acompanhar a mobilidade de membros da família transnacional e da comunidade senegalesa em Lajeado no dia da apresentação da segunda filha 
de Mame e Mohamed. No dia da apresentação do bebê de Mame, em 13 de janeiro de 2019, que começou às sete da manhã, o casal ofereceu comida o dia todo, preparada por uma amiga senegalesa da família que veio de Caxias do Sul para participar da festa. Nesse evento, a comunidade de senegaleses de Lajeado e de Caxias do Sul, onde Mohamed morava, vestia trajes típicos do Senegal. Mame usava um vestido colorido que seu irmão, costureiro, enviou do Senegal especialmente para a ocasião. Mame e sua primeira filha, Arame, vestem roupas confeccionadas pelo irmão dela no Senegal, fato elucidativo da qualidade das relações familiares transnacionais, nas quais os que ficam no país de origem também habitam, o que corresponde ao que Salazar e Glick-Schiller (2014) chamam de campo social transnacional.

Acerca do significado das roupas, trata Buggenhagen $(2011 ; 2012)$. A autora argumenta que para as mulheres as roupas são formas de exibir a riqueza utilizada para superar experiências de perda e violações nas relações introduzidas pelos nascimentos, mortes e casamentos. Vestir-se bem é ocupar o status de mulher de recursos, o desejo de honrar seu líder espiritual, e sua personalidade moral como piedosa e justa. Os vestidos individualizados são também uma maneira de se distinguir dos outros durante as cerimônias familiares. No Senegal, o vestido que a mulher usa torna a riqueza visível, transmitindo o potencial invisível das mulheres como produtoras e portadoras da história. As roupas são a linguagem por meio da qual as mulheres criaram os laços de parentesco e afinidade, bem como a posição social (Buggenhagen, 2011).

Da mesma forma que acontece em Nova York (Buggenhagen, 2012), em Lajeado, durante os encontros e festividades religiosas murid, como a visita do Shaykh do Senegal, reuniões de associação, celebrações familiares e feriados muçulmanos, as mulheres se vestem elegantemente e cozinham enorme quantidade de comida, servida em atos de comensalidade. Na Copa do Mundo de Futebol em 2018, no jogo entre Colômbia e Senegal, fomos convidadas para almoçar com os senegaleses e observamos nesse evento que Mame não conseguiu assistir ao jogo porque ficou preparando a comida que iria ser oferecida no almoço aos convidados, a maioria senegaleses. Ajudada por um conterrâneo, fez o prato típico: thieboudienne, um peixe acompanhado de cenoura, aipim, abóbora e o arroz feito no caldo do peixe. Notamos, em diversas situações, que o preparo das comidas em eventos especiais é liderado por mulheres, auxiliadas por homens. Essas práticas fortalecem as redes de amizade que dão suporte aos projetos migratórios de senegaleses. Os atos de comensalidade promovidos por Mame representam formas de estreitar os laços entre os senegaleses, bem como as visitas que ela faz eventualmente a conterrâneas que residem em cidades próximas de Lajeado.

Rosander (2010) postula que como as mulheres têm mais restrições do que os homens pela ideologia de gênero predominante, elas respondem às 
pressões de gênero mobilizando sua habilidade de criar redes sociais no país em que se estabelecem e de manter as redes sociais em casa em combinação com uma prática religiosa diligente e esforços financeiros na diáspora. "Elas são socializadas desde os primeiros anos de vida para manter relacionamentos duradouros com outras pessoas. Integrar o público no privado, o profano no sagrado, e a moral nas realidades da vida é uma tarefa mais feminina do que masculina" (Rosander, 2010, p. 4).

A mulher senegalesa murid em Lajeado contribui na mediação com membros da família transnacional. Por meio dos aplicativos de celular, acompanham o movimento dos familiares no Senegal. Percebemos que Mame olha com emoção as fotos que os familiares postam, nelas visualizamos pessoas bem arrumadas, principalmente de mulheres, com turbantes e vestidos coloridos. As ligações telefônicas e as mensagens permitem contato permanente com parentes no Senegal que lhes dão o suporte emocional necessário para enfrentar os projetos migratórios. O marido de Yacine comenta que sua esposa fala todos os dias com seus filhos no Senegal.

Assim como desempenham o papel de mediar a comunicação com a família transnacional e com membros da comunidade de senegaleses no Rio Grande do Sul, as mulheres atuam vinculando práticas da cultura de origem ao contexto migratório. Observamos que Mame e, a partir de 2017, sua conterrânea Yacine, exibem em seus corpos, em Lajeado, as marcas de identidade com a cultura de origem, como o turbante colorido, as roupas e as faixas de tecido nas costas, onde carregam os bebês. Essa prática cultural simboliza, à luz das teorias de Salazar e Glick-Schiller (2014), a conexão dos migrantes com o modo de vida na localidade de origem, reconfigurada no local onde se estabelecem. O que se mobiliza não são apenas pessoas, mas representações sociais acerca de práticas culturais.

A língua é também um elemento que vincula as mulheres senegalesas ao país de origem - elas se comunicam na língua wolof. Cabe então a seus maridos intervir na comunicação de suas esposas com membros da sociedade de acolhida. Percebemos que essas duas senegalesas entendem mais o português do que falam. Seus maridos, ainda que não falem fluentemente o português, atuam como mediadores entre suas esposas e as pessoas da cidade. Em mais de uma ocasião escutamos Mohamed dizendo que Mame não aprende o idioma português, apesar de fazer curso desde que chegou. Ambas as senegalesas que moram em Lajeado têm dificuldade em se comunicar em português. Em nossos encontros com Yacine, ela chama o marido para que participe como mediador da conversa.

O apoio nas dificuldades de comunicação das mulheres migrantes com pessoas da cidade foi observado em situações onde elas precisam de 
atendimento médico em Lajeado e os maridos as acompanham. Mohamed e Mame fecham a Loja e se dirigem ao posto de saúde. Mame prefere ir com o marido ao médico porque ele medeia a comunicação entre médico e paciente. Nesse contexto, os maridos dão voz aos sentimentos de dor e às emoções que as mulheres experimentam na condição de migrantes. A demanda por atendimento médico das migrantes durante a gravidez "exige do poder público disposição para reaprender caminhos para fornecer acessos à possibilidade de resolução de problemas decorrentes da imigração e dos fluxos de vida" (Jardim, 2017, p. 201).

Enfim, nas trajetórias de vida das senegalesas Mame e Yacine notamos que elas não manifestam sinais de autonomia, entendida por Rosander (2010) como a possibilidade de agir de acordo com formas de comportamento que podem ser contrárias a determinado sistema social, gerando espaço de manobra para atuar de forma autônoma. O comportamento das senegalesas é inibido pela ideologia religiosa que enfatiza a submissão e a obediência das mulheres aos homens (Rosander, 2010). Situação que destoa de experiências de mulheres no cenário migratório na condição de sujeitos autônomos (Rodrigues, Vasconcelos, 2012), como são as comerciantes senegalesas em Tenerife, Espanha, das que trata Rosander (2010). Essa autora assinala que quando as mulheres obtêm novas oportunidades econômicas tendem a mudar, aos poucos, a ideologia religiosa murid de gênero, que prega a superioridade dos homens sobre as mulheres.

\section{Considerações finais}

Neste artigo em que tomamos como foco a Loja de Mohamed e as relações que se constroem nela e a partir dela para pensar as experiências migratórias de senegaleses que residem na cidade de Lajeado, observamos como as diversas dimensões da vida desses migrantes são perpassadas pela ideologia religiosa da confraria murid. Essa confraria está presente nesse espaço tanto nos objetos que expressam a identidade religiosa do proprietário da Loja e de seus conterrâneos, quanto nas práticas que perpassam relações de gênero e as relações de trabalho. Destacamos que nas relações de gênero que dão suporte aos projetos migratórios, os papéis que homens e mulheres assumem são dominados pelos preceitos murids. Assim como notamos também que nas indústrias e no comércio em que os migrantes senegaleses atuam, é iminente a influência religiosa.

Ao acompanhar a trajetória de senegaleses e senegalesas conhecidos por intermédio de Mohamed, conseguimos nos aproximar das diferenças de gênero. Observamos nessas experiências migratórias de senegaleses que a atuação das mulheres se fundamenta em uma desigualdade de gênero instituída culturalmente pelo muridismo: a divisão entre os sexos está na 
"ordem das coisas" (Bourdieu, 2003, p. 17). Na abordagem, rompemos com o essencialismo, enfatizando em especificidades dessas trajetórias as relações de gênero, considerando o protagonismo das que permanecem no país de origem e das que migram para Lajeado. Mostramos também, em diálogo com a literatura do assunto, que a realidade das mulheres migrantes senegalesas em Lajeado lembra a trajetória de senegalesas em outros contextos migratórios.

Como pano de fundo, a Loja representa um espaço onde ocorrem conexões transnacionais que dão suporte a projetos migratórios de senegaleses fundamentados nos princípios religiosos de solidariedade com o outro. Dessa perspectiva, todos são irmãos, independentemente do país ou do credo religioso. Os senegaleses murids se solidarizam com os problemas e as dificuldades das pessoas através das orações, pregam a paz mundial. Assim, as vidas desses migrantes senegaleses são construídas com base em interconexões sociais que transpassam fronteiras internacionais, nas quais o componente religioso é norteador. Apesar de esses migrantes se situarem numa pequena cidade, esta experiência é influenciada por conexões transnacionais, familiares e religiosas, favorecidas pelo avanço nas tecnologias da comunicação e por políticas públicas migratórias de âmbito nacional, municipal e transnacional.

\section{Referências}

BABOU, Cheikh Anta. Migration and Cultural Change: Money, "Caste", Gender, and Social Status among Senegalese Female Hair Braiders in the United States. Africa Today, v. 55, n. 2, p. 3-22, 2008.

BOURDIEU, Pierre. A dominação masculina. Rio de Janeiro: Bertrand Brasil, 2003.

BUGGENHAGEN, Beth. Fashioning Piety: Women's Dress, Money, and Faith among Senegalese Muslims in New York City Indiana University. City \& Society, v. 24, n. 1, p. 84-104, 2012.

BUGGENHAGEN, Beth. Are births just "women's business"? Gift exchange, value, and global volatility in Muslim Senegal. Indiana University, Bloomington. American Ethnologist, v. 38, n. 4, p. 714-732, 2011.

BRAH, Avtar. Diferença, diversidade, diferenciação. Cadernos Pagu, v. 26, p. 329376, janeiro-junho 2006.

DELEUZE, Gilles. A filosofia crítica de Kant. Lisboa, Portugal: Edições 70, 2009.

GLICK-SCHILLER, Nina; CAGLAR, Ayse. Introduction: Migrants and cities. In: GLICK-SCHILLER, Nina; CAGLAR, Ayse (eds.). Locating migration: rescaling cities and migrants. New York: Cornell University Press, 2011, p. 1-19.

GUIJARRO, Ester Massó. Islam y género en la diáspora murid: mirada poscolonial a feminismos y migraciones Methaodos. Revista de Ciencias Sociales, v. 2, n. 1, p. 88-104, 2014. 
HEREDIA, Vania; GONÇALVES, Maria do Carmo. Deslocamentos populacionais no sul do Brasil: o caso dos senegaleses. In: TEDESCO, João Carlos; KLEIDERMACHER, Gisele (orgs.). A imigração senegalesa no Brasil e na Argentina: múltiplos olhares. Porto Alegre: EST Edições, 2017, p. 209-228.

HEREDIA, Vania; PANDOLFI, Bruna. Migrações Internacionais: o caso dos senegaleses em Caxias do Sul. In: HEREDIA, Vania B. M. (org.). Migrações Internacionais: o caso dos senegaleses no sul do Brasil. Caxias do Sul: BelasLetras, 2015, p. 95-113.

JARDIM, Denise F.. Imigração ou refugiados? Tecnologias de controle e as fronteiras. Jundiaí: Paco Editorial, 2017.

MARINUCCI, Roberto. Feminization of migration? REMHU, Revista Interdisciplinar da Mobilidade Humana, v. 15, n. 29, p. 5-22, 2007.

MEJÍA, Margarita Rosa Gaviria; CAZAROTTO, Rosmari T. O papel das mulheres imigrantes na família transnacional que mobiliza a migração haitiana no Brasil. Revista Pós-Ciências Sociais, v. 14, p. 171-189, 2017.

MIRANDA, Adelina. Editorial. Revue européenne des migrations internationales, v. 31, n. 1, p. 7-14, 2015.

NDIAYE, Abdou; GONÇALVES, Maria do Carmo; MOOJEN, Vanessa. Terenga! Impressões construídas numa viagem ao Senegal. In: HEREDIA, Vania B. M. (org.). Migrações Internacionais: o caso dos senegaleses no sul do Brasil. Caxias do Sul: Belas-Letras, 2015, p. 263-284.

PINHEIRO-MACHADO, Rosana. Made in China: (in)formalidades, pirataria e redes sociais na rota China-Paraguai-Brasil. São Paulo: Hucitec, Anpocs, 2011.

RODRIGUES, Francilene dos S; VASCONCELOS, lana S. Migração, gênero e empoderamento das migrantes na Pan-Amazônia. In: SILVA, Sidney (org.) Migrações na Pan-Amazônia: fluxos, fronteiras e processos socioculturais. São Paulo: Hucitec; Manaus: Papeam, 2012, p. 221-257.

ROMERO, Fanny. Islã, parentesco e ritual na irmandade religiosa Mouridiyya: percursos da etnografia no context da imigração de africanos senegaleses no Brasil. In: TEDESCO, João Carlos; KLEIDERMACHER, Gisele (orgs.). A imigração senegalesa no Brasil e na Argentina: múltiplos olhares. Porto Alegre: EST Edições, 2017, p. 275-277.

ROSANDER, Eva Evers. Gender relations and female autonomy among Senegalese migrants in Spain: three cases from Tenerife. African and Black Diaspora: An International Journal, v. 3, n. 1, p. 91-107, January 2010.

SAKHO, Pape; DIOP, Rosalie; MBOUP, Bara; DIADIOU, Diodio. A emigração internacional senegalesa: das casas no campo às cidades litorâneas. In: HERÉDIA, Vânia Beatriz Merlotti (org.). Migrações Internacionais: o caso dos senegaleses no sul do Brasil. Caxias do Sul: Belas-Letras, 2015, p. 23-49.

SALAZAR, Noel B.; GLICK-SCHILLER, Nina. Introduction. Regimes of mobility across the globe. In: SALAZAR, Noel B.; GLICK-SCHILLER, Nina (eds.). Regimes of mobility. Imaginaries and Relationalities of Power. New York (USA): Routledge, 2014. 
SEYFERTH, Giralda. A invenção da raça e o poder discricionário dos estereótipos. Anuário Antropológico, v. 18, n. 1, p. 175-203, 1994.

SOARES, Maria de Jesus. A vez e a voz da mulher imigrante portuguesa. In: MARUJO Manuela; BAPTISTA, Aida; NUNES, Rosana (orgs.). The Voice and Choice of Portuguese Immigrant. Toronto-CA: Universidade de Toronto, 2005, p. 11-18.

SOUSA, Sandra Maria Nascimento. Gênero e (des)locamentos: "O céu de Suely". Revista PósCiências Sociais, v. 8, n. 16, p. 145-154, 2011.

TEDESCO, João Carlos. Apresentação Imigração senegalesa no Brasil. In: TEDESCO, João Carlos; KLEIDERMACHER, Gisele (orgs.). A imigração senegalesa no Brasil e na Argentina: múltiplos olhares. Porto Alegre: EST Edições, 2017, p. 178-184.

TEDESCO, João Carlos; KLEIDERMACHER, Gisele. Introdução geral a imigração senegalesa no Brasil e na Argentina: múltiplos olhares. In: TEDESCO, João Carlos; KLEIDERMACHER, Gisele (orgs.). A imigração senegalesa no Brasil e na Argentina: múltiplos olhares. Porto Alegre: EST Edições, 2017, p. 9-17.

UEBEL, Roberto Rodolfo Georg. Senegaleses no Rio Grande do Sul: panorama e perfil do novo fluxo migratório "África-Sul do Brasil". In: TEDESCO, João Carlos; KLEIDERMACHER, Gisele (orgs.). A imigração senegalesa no Brasil e na Argentina: múltiplos olhares. Porto Alegre: EST Edições, 2017, p. 185-207.

UEBEL, Roberto Rodolfo Georg. Panorama e perfil da imigração senegalesa no Rio Grande do Sul no início do século XXI. Boletim Geográfico do Rio Grande do Sul, Porto Alegre, n. 28, p. 56-77, set. 2016.

WINTERS, Nanneke. Responsibility, Mobility, and Power: Translocal Carework Negotiations of Nicaraguan Families. International Migration Review, v. 48, n. 2, p. 415-441, 2014. 